\title{
Darmstadt Rotor No. 2, II: Design of Leaning Rotor Blades
}

\author{
Jörg Bergner and Dietmar K. Hennecke \\ Darmstadt University of Technology, Darmstadt, Germany
}

\author{
Martin Hoeger and Karl Engel \\ MTU Aero Engines, Munich, Germany
}

For Darmstadt University of Technology's axial singlestage transonic compressor rig, a new three-dimensional aft-swept rotor was designed and manufactured at MTU Aero Engines in Munich, Germany. The application of carbon fiber-reinforced plastic made it possible to overcome structural constraints and therefore to further increase the amount of lean and sweep of the blade. The aim of the design was to improve the mechanical stability at operation that is close to stall.

To avoid the hazard of rubbing at the blade tip, which is found especially at off-design operating conditions close to the stability limit of the compression system, aft-sweep was introduced together with excessive backward lean.

This article reports an investigation of the impact of various amounts of lean on the aerodynamic behavior of the compressor stage on the basis of steady-state Navier-Stokes simulations. The results indicate that high backward lean promotes an undesirable redistribution of mass flow and gives rise to a basic change in the shock pattern, whereas a forward-leaning geometry results in the development of a highly back-swept shock front. However, the disadvantage is a decrease in shock strength and efficiency.

Keywords Bow shock, Rotor design lean, Sweep, Transonic compressor

The Department of Gas Turbines and Flight Propulsion at Darmstadt University of Technology in Darmstadt, Germany,

Received 25 June 2002; accepted 1 July 2002.

The authors thank Bertram Stubert and Bernard Brouillet of MTU Aero Engines for their helpful advice in generating the grid and performing the calculations.

Address correspondence to Jörg Bergner, Darmstadt University of Technology, Fachbereich 16, Maschinenbau, Petersenstrasse 30, Darmstadt, D-64287, Germany. E-mail: bergner@gfa.tu-darmstadt.de

has been operating the high-speed transonic compressor rigwhich represents a typical front-stage of a commercial turbofan, high-pressure compressor-since the early 1990s. The main purpose of the test stand is to establish a database for computational fluid dynamics (CFD) code validation as well as to serve as a test bed for new materials.

The initial rotor no. 1 was designed as a bladed disk (Blisk) made of titanium with conventionally stacked blade sections. The encouraging experience with vanes made of composites led to the use of carbon fiber-reinforced plastic (CFRP) to construct a high-speed compressor rotor with swept blades. The material's obvious benefits-reduced density combined with strength similar to that of titanium alloys - allowed for rotor blade geometries with amounts of sweep and lean that are not possible in a titanium-based design.

Because of lack of experience in predicting blade tip bending, especially under unsteady aerodynamic load at stall, an aft-swept design was chosen for Rotor No. 2 so as to prevent severe damage in case of rubbing. Rig tests partly presented by Kablitz and colleagues (2002) successfully demonstrated reliable operation of the rotor up to the highest speeds. Because the main focus of the project was to gain experience in building three-dimensional rotor blade geometries using CFRP, the high amount of lean was chosen independent of aerodynamic necessity. The results of the measurements (Kablitz et al., 2002) provided a reason to investigate the aerodynamic impact of significant variations in lean.

\section{ROTOR GEOMETRIES INVESTIGATED}

\section{Darmstadt Rotor No. 2}

Details concerning the mechanical design and the manufacturing can be found in the work of Pirker and colleagues (2002) and Blaha and colleagues (2000). The aerodynamic design intent for Rotor No. 2 was to influence the shock structure by sweeping the leading edge aft so as to minimize loss. Tip speed, mass flow rate, and pressure ratio at the design-point are the 


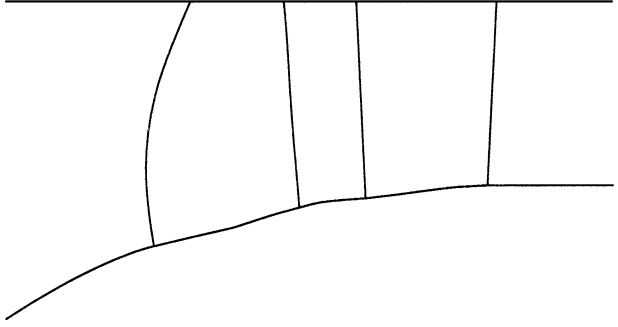

FIGURE 1

Meridional view of Rotor No. 2.

same as for Rotor No. 1. To ensure the option of traverse probes between rotor and stator, the axial dimension of the rotor had to be held almost constant (Fig. 1), so most of the aft-sweep had to be introduced by aft-lean (Fig. 2a). Figure 3 lists the major design parameters of the compressor utilizing Rotor No. 2. Further information on the aerodynamic design and the tools used for it can be found in the paper by Blaha and colleagues (2000).

For the analysis presented in this article, two variations in the lean of the Rotor No. 2 blade geometry were generated. In the first step, Rotor No. 2's defining airfoil cross-sections (Fig. 2a) were radially stacked (Fig. 2b), and in the second step, they were inversely stacked (Fig. 2c), leading to a forward-leaning blade geometry with the same radial distribution but inverted-leaning angles (Fig. 4). No attempt was made to modify the stagger or airfoil parameters to take into account the altered flow field that had been caused by the heavily varied lean.

\section{COMPUTATIONS}

For the three rotor geometries, steady-state Reynoldsaveraged Navier-Stokes (RANS) computations at design speed were conducted.

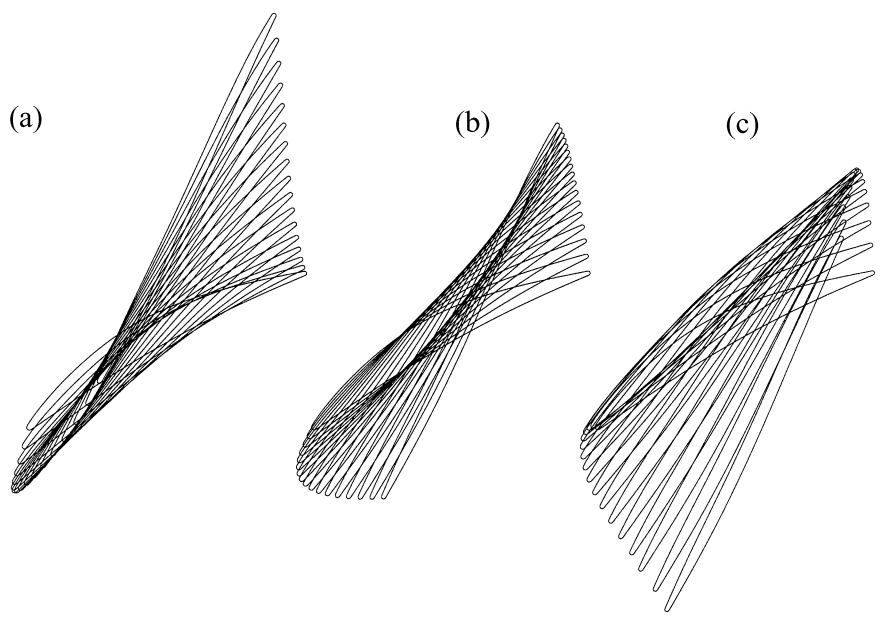

FIGURE 2

Cross-sections of the rotor blade. Lean variations: (a) Rotor No. 2 (aft-leaning); (b) radially stacked rotor; (c) forward-leaning rotor.

\begin{tabular}{|lc|}
\hline & \\
\hline Pressure ratio & 1.5 \\
Corrected mass flow rate & $16.0 \mathrm{~kg} / \mathrm{sec}$ \\
Corrected tip speed & $398 \mathrm{~m} / \mathrm{sec}$ \\
Relative rotor inlet Mach number at tip & 1.35 \\
Relative rotor inlet Mach number at hub & 0.70 \\
Shaft speed & $20.000 \mathrm{rpm}$ \\
Tip diameter & $0.38 \mathrm{~m}$ \\
Number of blades & 16 \\
Inlet hub-to- tip ratio & 0.51 \\
Mean aspect ratio of Rotor No. 2 & 0.98 \\
Rotor No. 2 solidity (hub / mid / tip) & $1.7 / 1.4 / 1.1$ \\
\hline
\end{tabular}

FIGURE 3

Design parameters of the compressor.

\section{Solver}

Trace_S, an explicit cell-centered, second-order-accurate, finite-volume scheme was used to solve the RANS equations. To speed up convergence to steady-state, local time-stepping, residual smoothing, and successive mesh refinement were applied (Fritsch et al., 1997).

A high Reynolds $\kappa-\varepsilon$ model with wall functions was used. All simulations were run in fully turbulent mode. International Standard Atmosphere standard conditions with purely axial flow were assumed at the inflow. A rather pronounced incoming casing boundary layer was prescribed by a total pressure profile. The boundary layer at the hub was neglected because of the strong acceleration over the spinner. The measured turbulence intensity of $1 \%$ was prescribed at the inflow boundary. At the

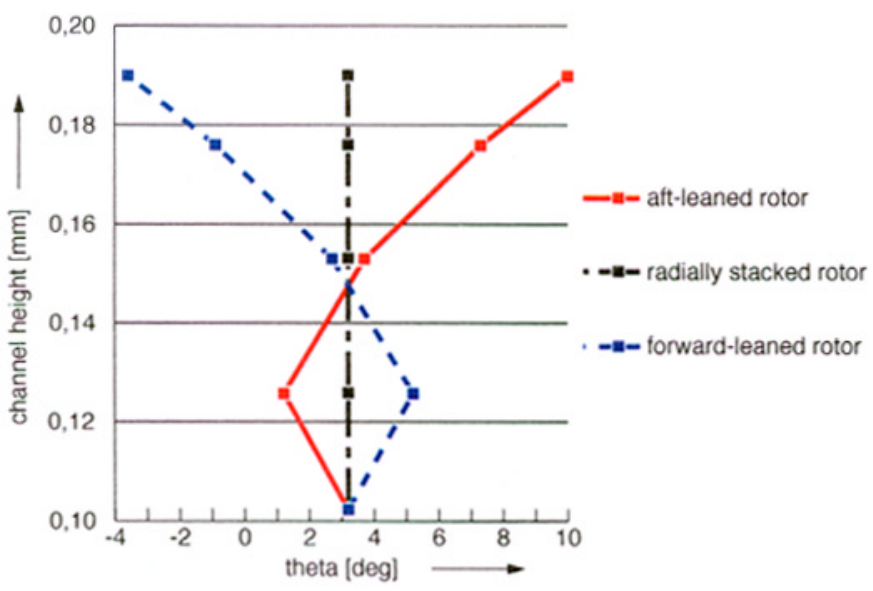

FIGURE 4

Leaning angles of the investigated geometries. 

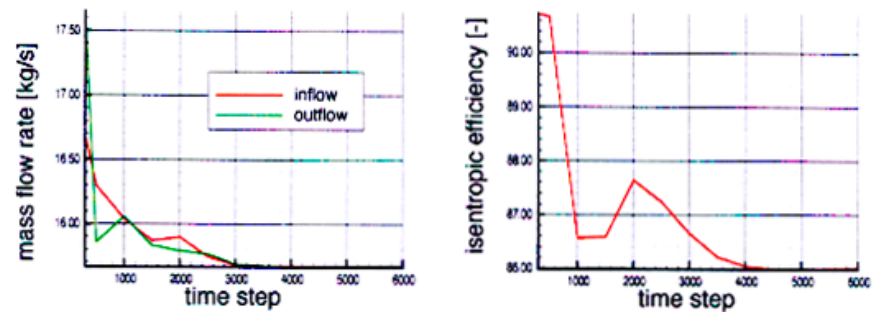

FIGURE 5

Typical process to convergence.

outlet, a radial equilibrium was assumed and the average static pressure was fixed at mid-span.

Every computation ran for 6000 time steps, which resulted in an execution time of approximately 24 (Central Processing Unit) h on a Silicon Graphics, Inc., Octane. The achieved state of convergence can be deduced from Figure 5, which may be taken as being representative of all the calculations discussed in this article.

\section{Grids}

An identical block-structured $\mathrm{O}-\mathrm{H}$ grid was used, as is summarized in Figure 6, and it adds up to a total of 630,000 nodes. The nominal clearance amounts to $1 \mathrm{~mm}$ ( $1 \%$ channel height) at the rotor tip gap (Fig. 7).

The relative motion of the rotor and casing was included, but the cavity between rotor and the stator at the hub was neglected.The grid density was refined at the hub and casing so as to increase the resolution of the boundary layers as well as the passage shock (see Figs. 7-9).

\begin{tabular}{|llll|}
\hline Number of Nodes: & Axial & Pitchwise & Radial \\
\hline Rotor H-grid & 104 & 32 & 64 \\
Upstream from rotor & 28 & & \\
In rotor passage & 64 & & \\
Downstream from rotor & 12 & & 64 \\
Stator H-grid & 104 & 32 & \\
Upstream from stator & 12 & & \\
$\quad$ In stator passage & 64 & & 64 \\
Downstream from stator & 28 & & 64 \\
Rotor O-grid & 128 & 8 & 8 \\
Stator O-grid & 128 & 8 & \\
O-grid in tip-gap & 128 & 6 & \\
& & & \\
\hline
\end{tabular}

FIGURE 6

Grid topology.

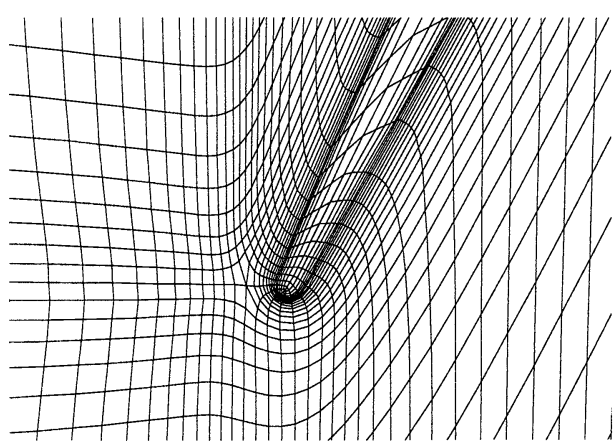

FIGURE 7

Grid at tipgap.

\section{ANALYSIS}

In Figure 10 the computed stage-performances of the three investigated rotor-blade geometries are displayed together with the measured speed line of Rotor No. 2 at design speed. Details regarding the experimental setup can be found in Kablitz and colleagues (2002). The calculations conducted for the Rotor No. 2 geometry conformed closely with the experiment. For the radially and the inversely stacked rotors, additional simulations were run to determine the characteristics of their speed lines.

The predicted pressure ratio of the radially stacked rotor was slightly higher than that of Rotor No. 2, whereas the forwardleaning rotor generated a significantly lower pressure rise. The peak efficiency of the forward-leaning rotor appears to be similar to that of Rotor No. 2, although the corresponding mass flow rate is lower. The simulation of the radially stacked rotor predicts an isentropic efficiency that is approximately $0.5 \%$ higher than that of Rotor No. 2. The following discussion compares computations that have a prescribed static backpressure of $1.22 * 10^{5}$ pascals, leading to a total pressure ratio of about 1.43 .

Figure 11 shows the radial distribution of the stage's total pressure ratio. As expected, based on the stage performance

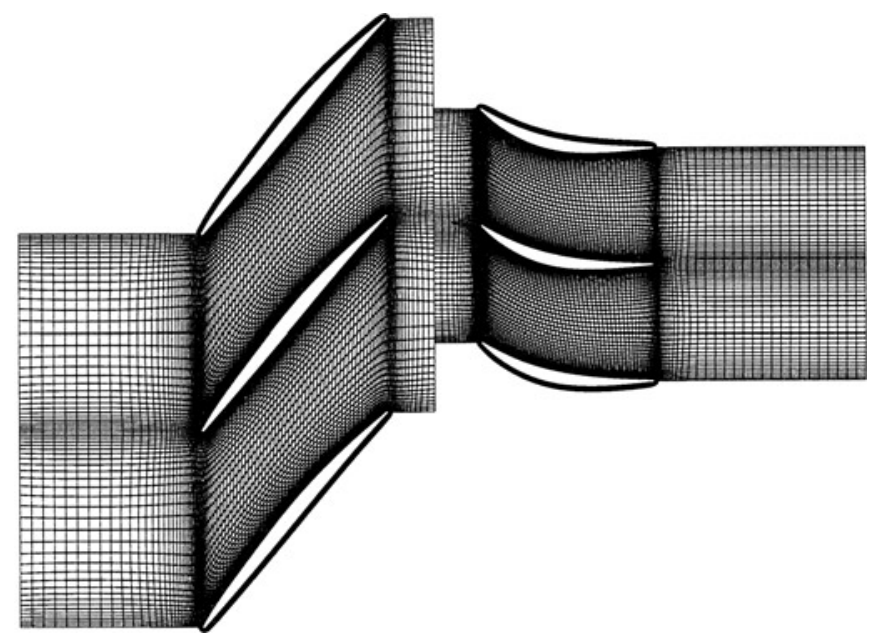

FIGURE 8

Blade-to-blade grid. 


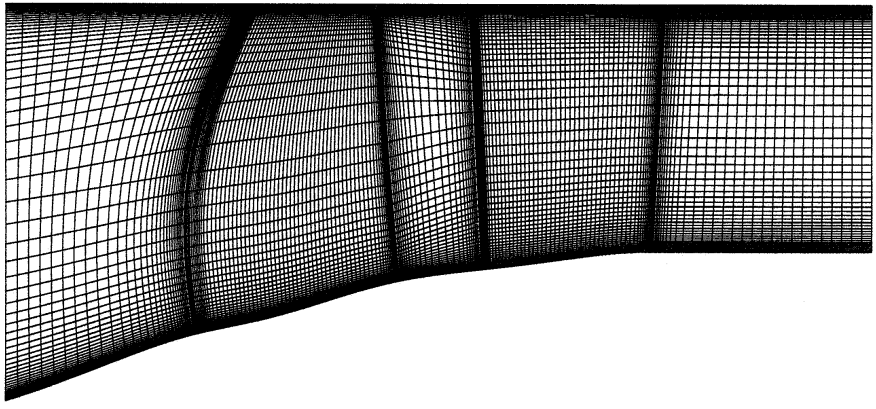

FIGURE 9

Meridional grid.

results, the radially stacked rotor delivered roughly the same radial pressure rise as Rotor No. 2 in terms of plot magnification. In the forward-leaning rotor, an improvement in pressure rise was observed from the hub to the mid-span. At the outer span, however, its level fell far below that of Rotor No. 2. In addition, the rotor loss coefficient (Fig. 12) increased between $30 \%$ and $90 \%$ in channel height and in the tip-clearance vortex region in the forward-leaning rotor, whereas the tip leakage losses decreased.
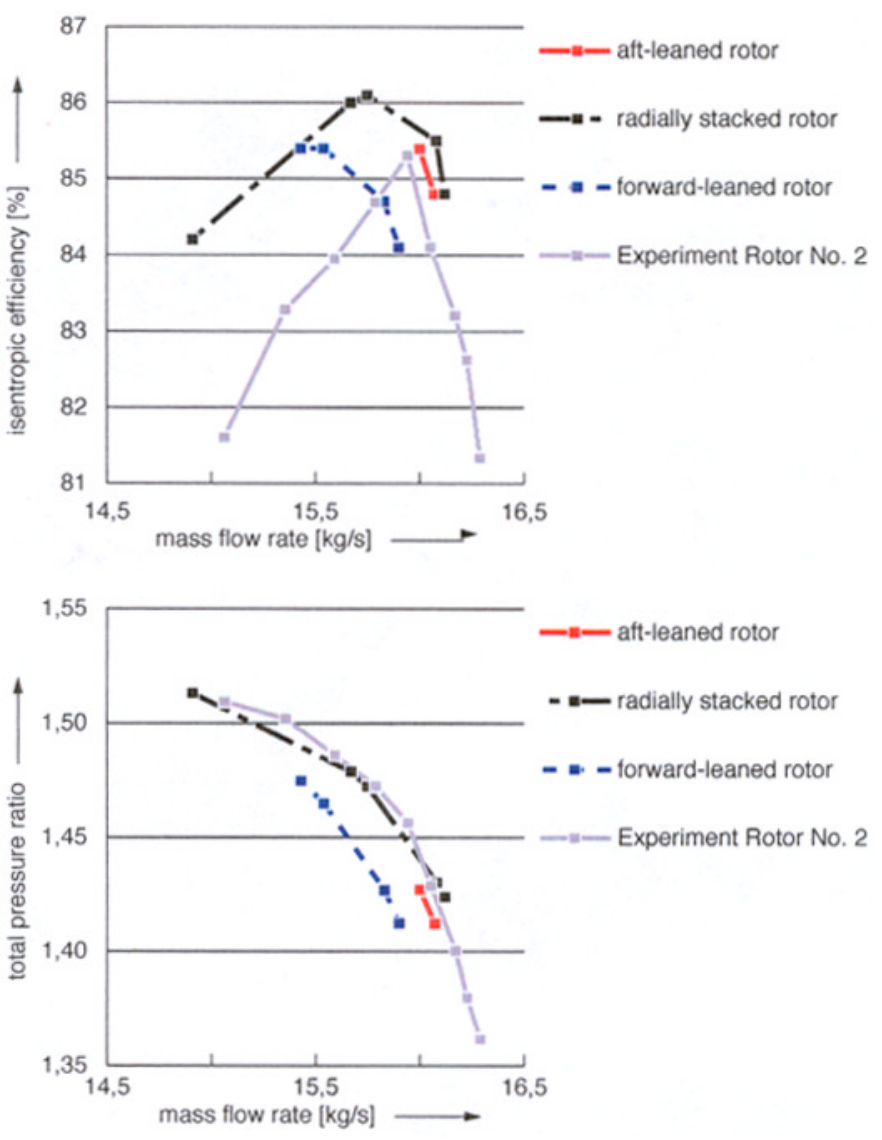

FIGURE 10

Stage performance at design speed.

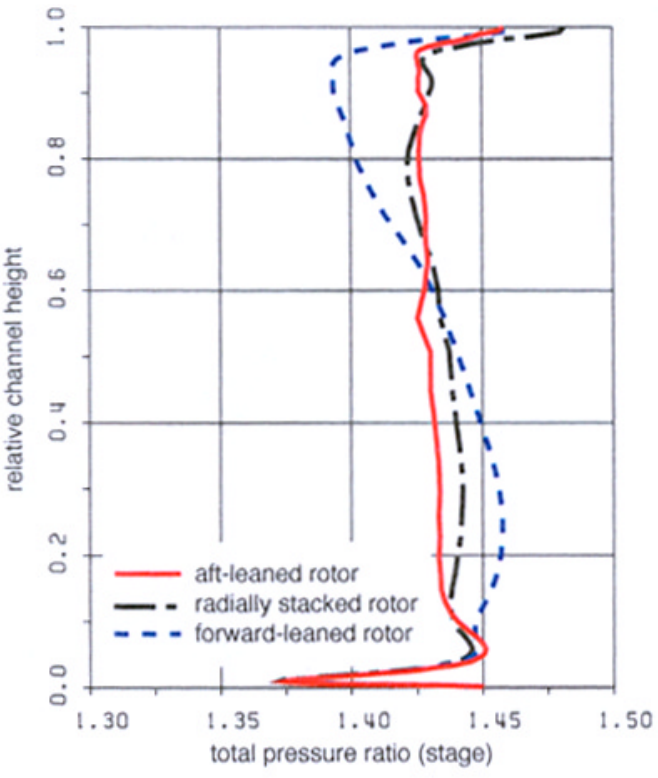

FIGURE 11

Radial distribution of the stage's total pressure ratios.

As expected on the basis of theory (Denton et al., 1999; Hah et al., 1998; Wadia et al., 1998), the altered pressure field between the rotor blades, which is caused by lean, led to a shift in mass flow toward the hub with increased aft-lean (Fig. 13), resulting in a relative reduction in velocity at the aft-leaning rotor's blade tip and thereby in increased incidence.

It is remarkable that in respect to the radially stacked blading, the magnitude of the decrease in velocity at mid-span of the forward-leaning rotor exceeded the increase in velocity of the

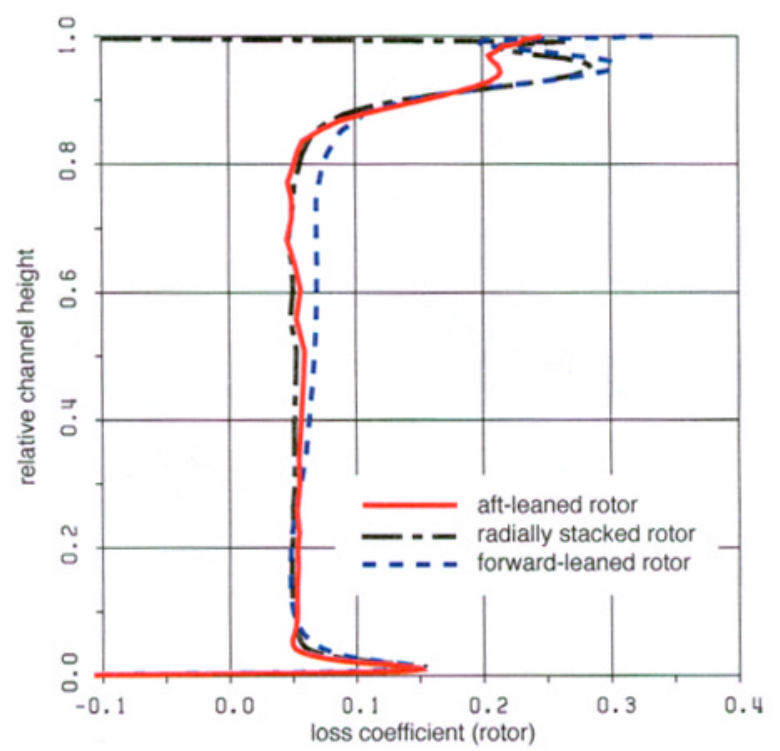

FIGURE 12

Radial distribution of rotor's loss coefficient. 


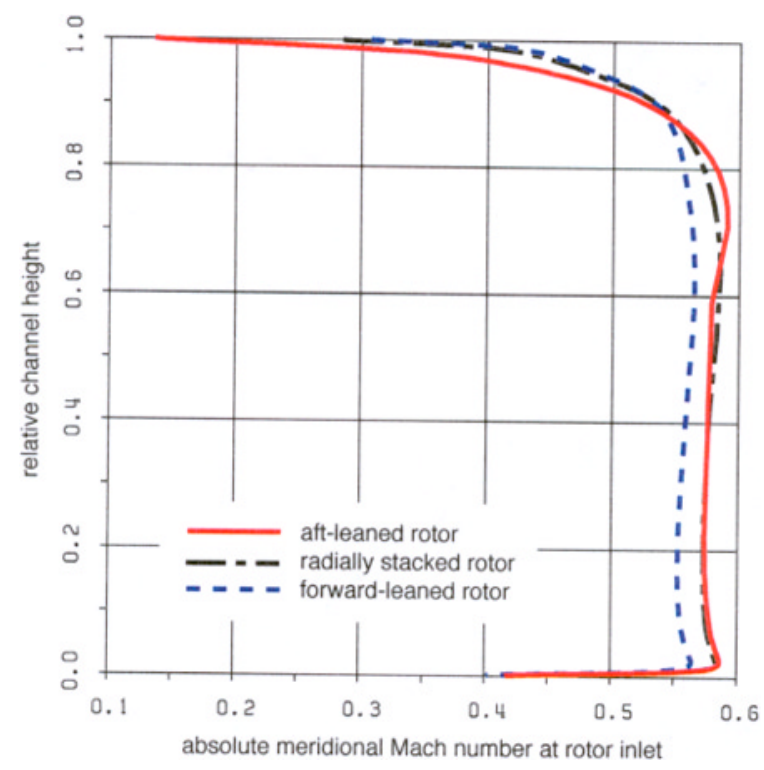

FIGURE 13

Radial distribution of the absolute Mach number at the rotor inlet.

aft-leaning rotor. In contrast to those findings was the absolute Mach number at the rotor exit, as shown in Figure 14. There, an opposite redistribution of the mass flow occurred. Also, the transported mass flow declined toward the tip in all investigated rotor geometries, corresponding to the evenly distributed total pressure ratio along the span, as shown in Figure 11.

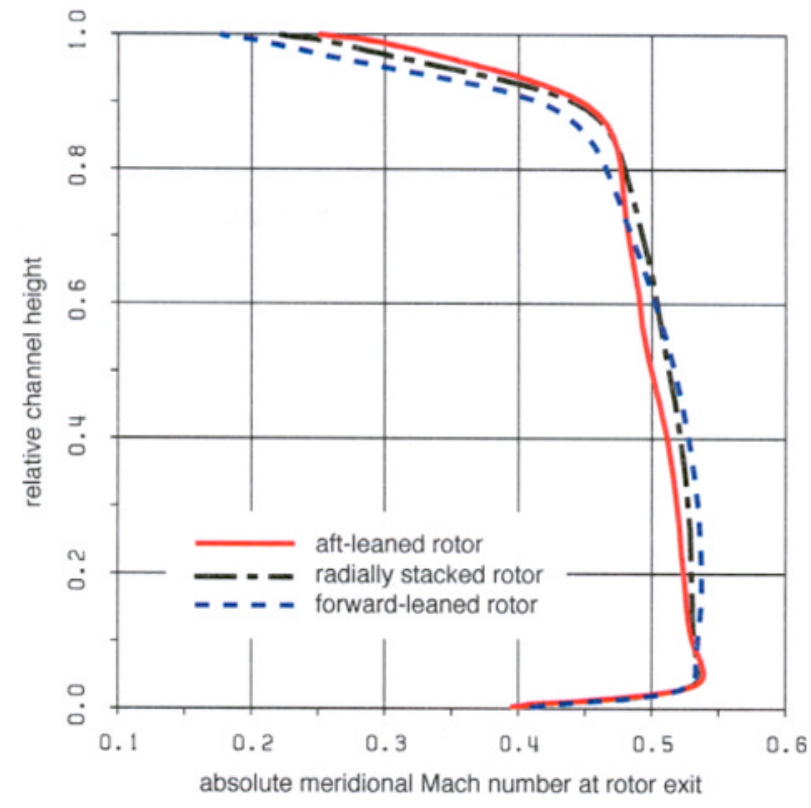

FIGURE 14

Radial distribution of the absolute Mach number at the rotor exit.
Rotor No. 2 itself, as described by Blaha (2000), suffered from a work deficiency at the tip, which was attributed to the radial flow migration which, in turn, was due to the aft-lean. The anticipated advantageous effect of the forward-leaning rotor on the radial distribution of the mass flow seemed to be overcompensated for by the nonuniform, radial work input and by the deflection resulting from the changed shock pattern.

Figures 15, 16, and 17 show the relative, isentropic profile Mach number at $90 \%, 52 \%$, and $10 \%$ channel height, respectively. As noted earlier, the reduced axial velocity at the tip led to an increased incidence.

It can be seen in Figure 15 that the shock became weaker and its location moved farther downstream with increased forward lean. Additionally, the preshock Mach number tended to rise. The remarkably high level of the isentropic Mach number at the trailing edge of all three rotor geometries, noticeably supersonic at the forward-leaning blading, explained the work deficiency.

Figure 16 illustrates that the higher mass flow in the lower half of the aft-leaning rotor's passage promoted a double-shock system. Because of the decreased rotor inlet Mach number at the mid-span, the forward-leaning rotor's shock strength was reduced, and the flow did not expand to a second shock. Near the hub (see Fig. 17), the shock was more intense and was located farther upstream with increased forward lean.

Considering the contour plots of the suction-side isentropic Mach numbers (Fig. 18), Rotor No. 2's two shock fronts, whereas

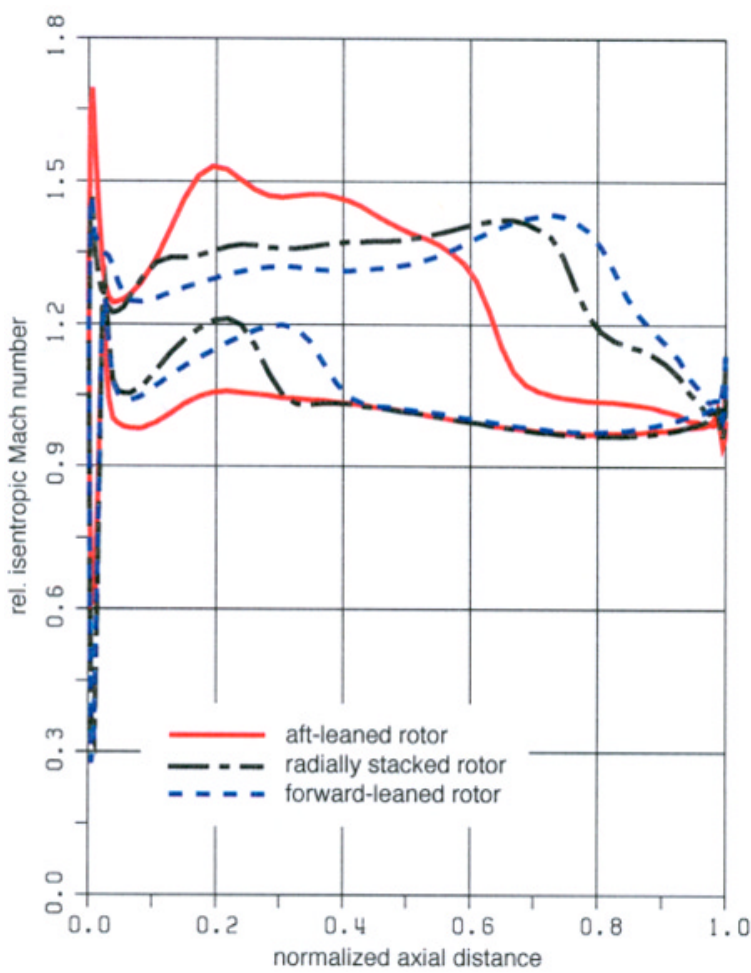

FIGURE 15

Relative isentropic Mach number at 90\% channel height. 


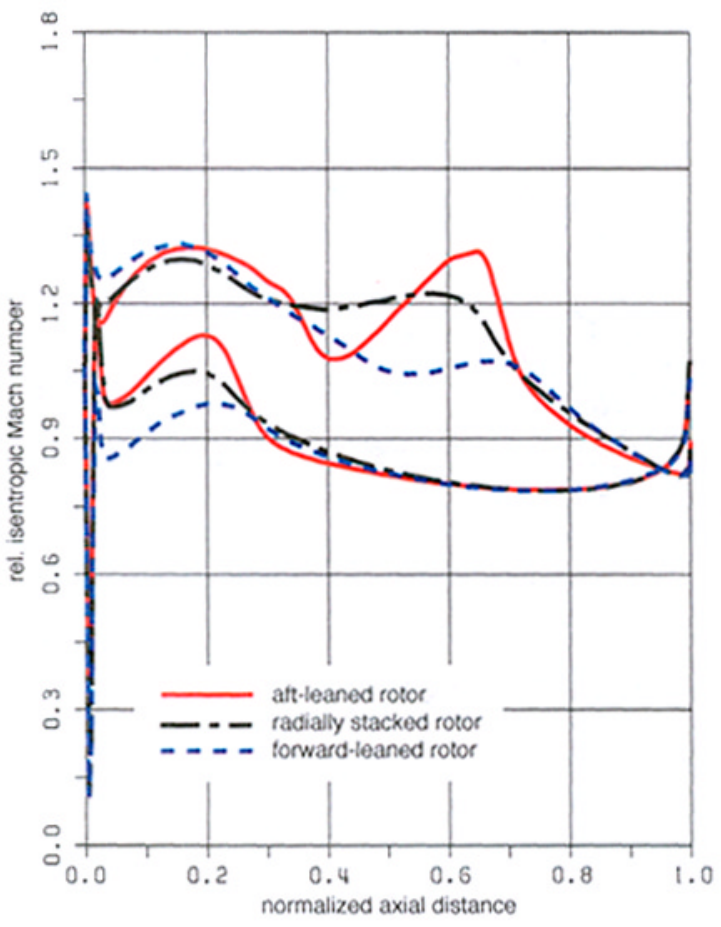

FIGURE 16

Relative isentropic Mach number at 52\% channel height.

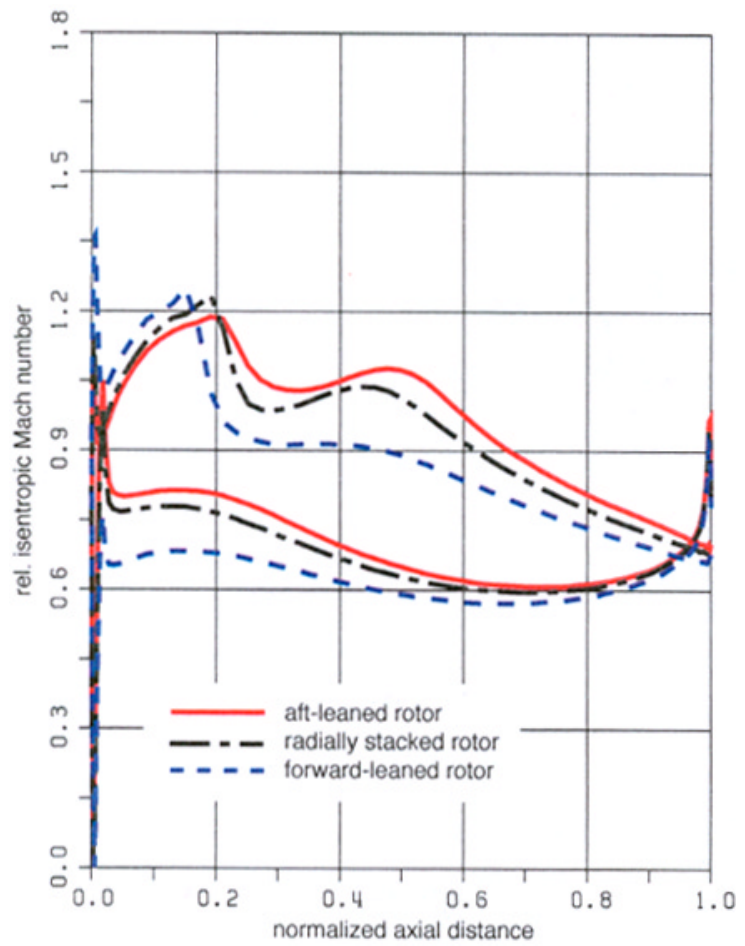

FIGURE 17

Relative isentropic Mach number at 10\% channel height.
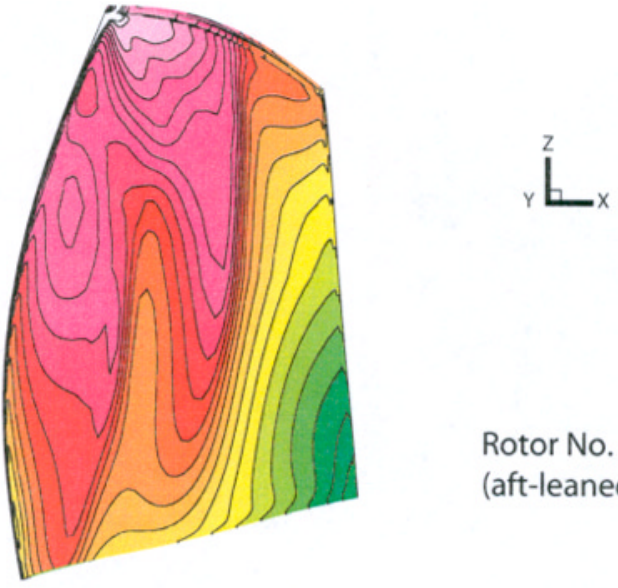

Rotor No. 2 (aft-leaned)
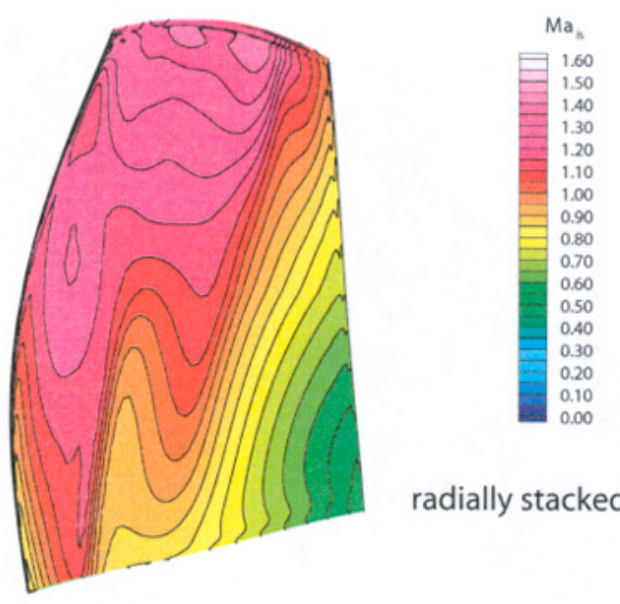

radially stacked rotor

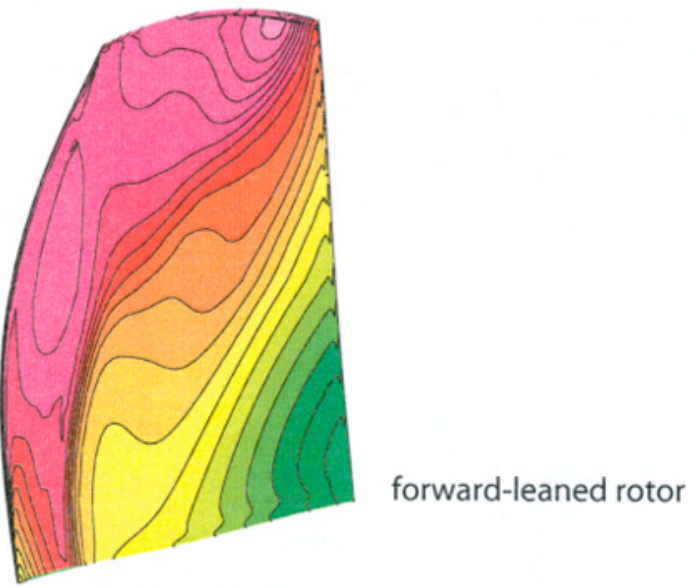

FIGURE 18

Suction side isentropic Mach number contours at $P i=1.43$.

almost radial, were slightly curved upstream. The increased lean promoted reduced strength and decreased inclination of the shock front at the tip, leading to a heavily aft-swept shock at the forward-leaning rotor. Figure 19 quantifies the sweep of the shock fronts on the suction surfaces, giving the measured angles relative to the $\mathrm{x}$ axis in Figure 18. 


\begin{tabular}{lcc|}
\hline & Hub & Tip \\
\hline Rotor No. 2 (aft-leaning) & $70^{\circ}-85^{\circ}$ & $76^{\circ}-90^{\circ}$ \\
Radially stacked rotor & $83^{\circ}$ & $72^{\circ}$ \\
Forward-leaning rotor & $-8^{\circ}-80^{\circ}$ & $45^{\circ}-80^{\circ}$ \\
\hline
\end{tabular}

FIGURE 19

Sweep-angles the shock front.

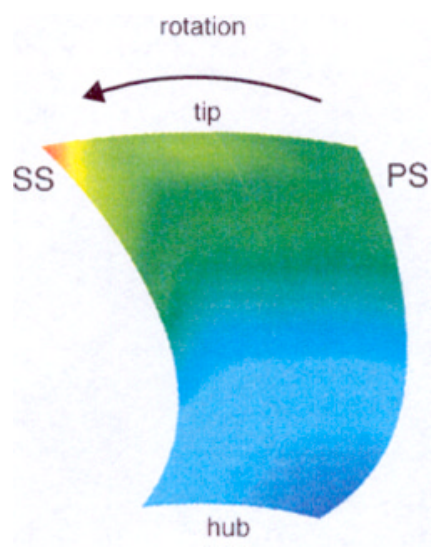

FIGURE 20

Isentropic Mach number near trailing edge, at axial plane as seen in Figure 21 (forward-leaning rotor).

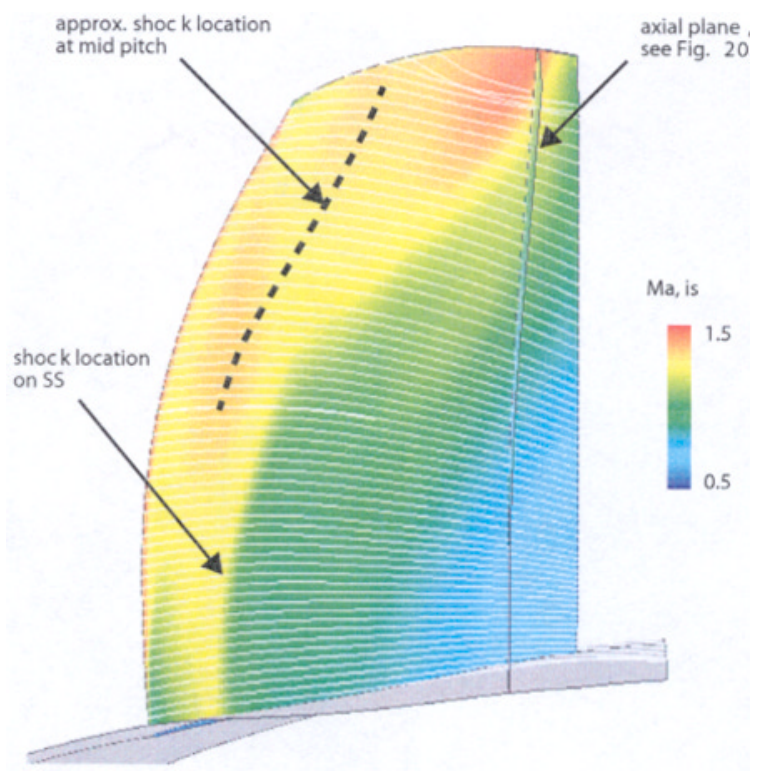

FIGURE 21

Streamlines at mid pitch (forward-leaning rotor).
As pointed out by Hah and colleagues (1998), the shock does not intersect the casing obliquely. Instead, it turns normal, as can be seen in Figure 20. Streamlines shown for the forward-leaning rotor at mid pitch (Fig. 21) are projected onto the meridional plane. They illustrate the mass flow's deflection in the rotor passage, which was pronounced at the aft-swept shock above the mid span. The forward-leaning rotor demonstrates the possibility of an enormous shock inclination, which is desired by many designers. The disadvantage of reduced shock strength and the resulting redistributed mass flow is that they destroy the efficiency benefits previously gained from the improved shock situation.

\section{CONCLUSIONS}

This numerical investigation of three-dimensional blade geometries in a high-speed transonic compressor rotor provides some insight into the ways in which lean controls the work input and the radial distribution of the mass flow.

It has been observed that a highly oblique shock front on the meridional plane is possible, but it has the disadvantage of forcing a strong radial migration of the flow to the hub, which in turn affects the efficiency gained from the shock's inclination. Further improvements can be expected from the optimization of the profile shapes certain three-dimensional blade applications.

\section{REFERENCES}

Blaha, C., Kablitz, S., Hennecke, D., Schmidt-Eisenlohr, U., Pirker, K., and Haselhoff, S. 2000. Numerical investigation of the flow in an aft-swept transonic compressor rotor. Proceedings of the ASME Turboexpo 2000, Paper 2000-GT-04090. Munich, Germany: ASME.

Denton, J. D., and Xu, L. 1999. Exploitation of 3D flow in turbomachinery. In Van den Braembusche, R. A., ed. Turbomachinery Blade Design Systems - Von Karman Institute for Fluid Dynamics.

Fritsch, G., Hoeger, M., Blaha, C., and Bauer, D. 1997. Viscous 3D compressor simulation on parallel architectures. AIAA Paper 97-2876.—: AIAA.

Hah, C., Puterbaugh, S. L., and Wadia, A. R. 1998. Control of shock structure and secondary flow field inside transonic compressor rotors through aerodynamic sweep. ASME Paper 98-GT-561. Proceedings of the ASME Turbo Expo 1998. Stockholm, Sweden.

Kablitz, S., Bergner, J., Hennecke, D. K., Beversdorff, M., and Schodl, R. 2002, February. Darmstadt Rotor No. 2. III: Experimental analysis of an aft-swept axial transonic compressor stage. Proceedings of ISROMAC 9. Honolulu, HI: ISROMAC.

Pirker, K., and Frischbier, J. 2002, February. Darmstadt Rotor No. 2. I: Design and stress analysis of a one-stage transonic composite compressor. Proceedings of ISROMAC 9. Honolulu, HI: ISROMAC.

Wadia, A. R., Szucs, P. N., and Crall, D. W. 1998. Inner workings of aerodynamic sweep. ASME Journal of Turbomachinery 120:671. 

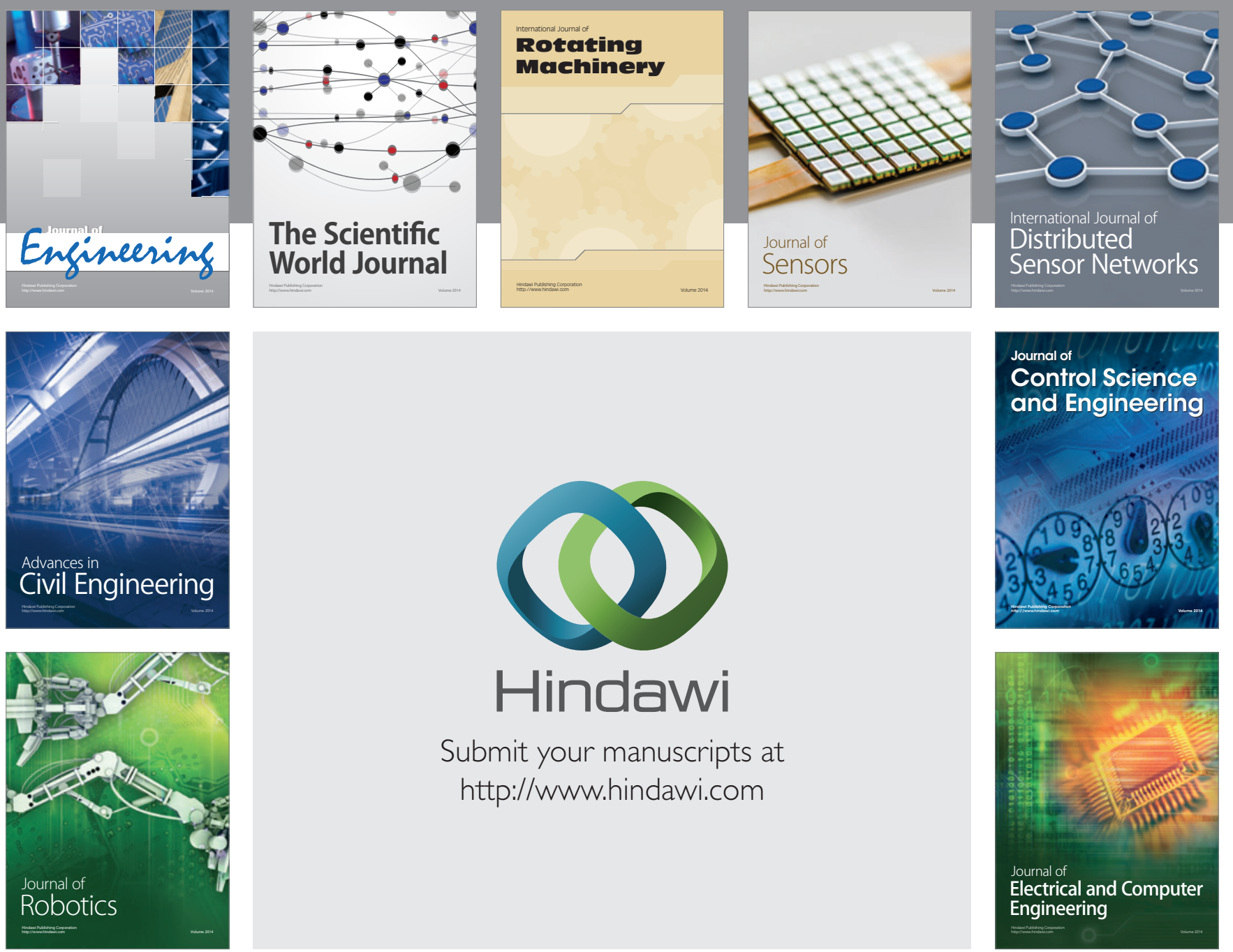

Submit your manuscripts at

http://www.hindawi.com
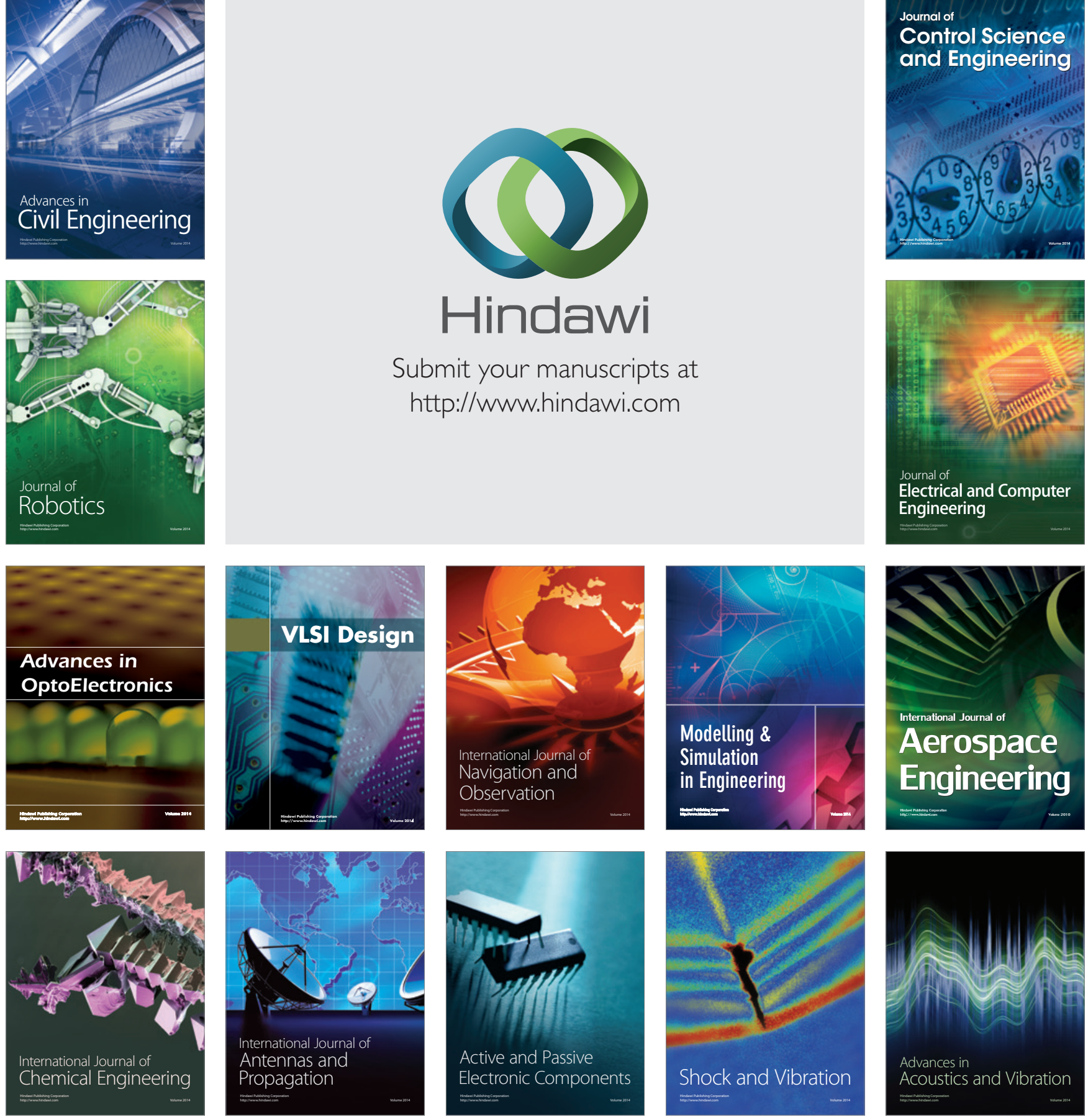